\title{
Ethanol extract from Artemisia vestita, a traditional Tibetan medicine, exerts anti-sepsis action through down-regulating the MAPK and NF- $\mathrm{kB}$ pathways
}

\author{
YANG SUN*, YI-HUA LI* ${ }^{*}$ XING-XIN WU, WEI ZHENG, ZONG-HUI GUO, \\ YANG LI, TING CHEN, ZI-CHUN HUA and QIANG XU \\ State Key Laboratory of Pharmaceutical Biotechnology, School of Life Sciences, \\ Nanjing University, 22 Han Kou Road, Nanjing 210093, P.R. China
}

Received December 20, 2005; Accepted January 30, 2006

\begin{abstract}
Artemisia vestita Wall., a traditional Tibetan medicine, has wide clinical application for inflammatory diseases. However, its molecular mechanism of antiinflammatory effect is poorly understood. In the present study, we investigated the anti-inflammatory activity and underlying mechanism of the ethanol extract from Artemisia vestita (AV-ext) on lipopolysaccharide (LPS)-induced sepsis. Pretreatment with AV-ext significantly decreased the levels of tumor necrosis factor- $\alpha$ (TNF- $\alpha$ ) in serum and liver and lung tissues, and improved the survival of mice with experimental sepsis. AV-ext also remarkably reduced the expression levels of TNF- $\alpha$, interleukin-1 13 and cyclooxygenase- 2 in LPSstimulated RAW 264.7 macrophages and dose dependently suppressed the activation of mitogen-activated protein kinases (MAPKs), such as p38, extracellular signal-regulated kinase (ERK1/2) and c-Jun $\mathrm{NH}_{2}$-terminal kinase (JNK). Furthermore, pretreatment with AV-ext dose dependently inhibited the activation of nuclear factor $-\kappa \mathrm{B}(\mathrm{NF}-\kappa \mathrm{B})$, as well as the degradation and phosphorylation of inhibitory $\kappa \mathrm{B}(\mathrm{I \kappa B})$ in LPS-activated RAW 264.7 macrophages. These results collectively reveal that $\mathrm{AV}$-ext inhibits $\mathrm{TNF}-\alpha$ release from macrophages by suppressing MAPK and NF-кB signaling pathways and suggest that AV-ext may be beneficial for the treatment of endotoxin shock or sepsis.
\end{abstract}

\section{Introduction}

Macrophages, as the primary target cells of lipopolysaccharide (LPS), play an important role in inflammatory diseases. LPS

Correspondence to: Dr Qiang Xu, School of Life Sciences, Nanjing University, 22 Han Kou Road, Nanjing 210093, P.R. China

E-mail:molpharm@163.com

${ }^{*}$ Contributed equally

Key words: sepsis, Artemisia vestita, tumor necrosis factor- $\alpha$, mitogen-activated protein kinases, NF- $\mathrm{KB}$ can trigger macrophages to secrete various proinflammatory cytokines, such as tumor necrosis factor- $\alpha$ (TNF- $\alpha)$, cyclooxygenase-2 (COX-2) and interleukin-1ß (IL-1ß). The overproduction of these inflammatory mediators, especially TNF- $\alpha$, usually accounts for the pathological outcomes of many diseases, including diabetes, chronic hepatitis and sepsis (1-3). Neutralization of TNF- $\alpha$ or IL-1ß could prevent the development of sepsis in some animal models (4). Multiple signaling molecules are activated in these inflammatory processes, some of which are involved in cytokine production, such as phosphatidylinositol 3-kinase, p38, extracellular signal-regulated kinase $1 / 2(\mathrm{ERK} 1 / 2)$, and c-Jun $\mathrm{NH}_{2}$-terminal kinase (JNK) (5). It is well known that transcription factor $\mathrm{NF}-\kappa \mathrm{B}$ plays a crucial role in the activation of inflammatory response genes, including $\mathrm{TNF}-\alpha$, inducible nitric oxide synthase (iNOS), IL-1ß and COX-2 (6,7). NF- $\mathrm{BB}$ is activated by a signal transduction cascade, accompanied by the activation of the inhibitor of NF- $\kappa \mathrm{B}$ kinase, in which I $\kappa \mathrm{B}$ is phosphorylated and degraded, and NF- $\mathrm{KB}$ is finally translocated to the nucleus. Increasing evidence reveals that the inhibition of $\mathrm{NF}-\kappa \mathrm{B}$ activity may lead to alleviating the severity of inflammatory diseases $(8,9)$. Therefore, understanding the molecular mechanisms involved in these pathways is an essential step towards countering the damaging effects of proinflammatory mediators.

The herb, Artemisia vestita, has been widely used in traditional Tibetan and Chinese medicine for a variety of inflammatory diseases, such as rheumatoid arthritis, contact dermatitis and sepsis (10). In previous studies, we demonstrated that AV-ext reduced the contact sensitivity in mice by down-regulating the activation, adhesion and metalloproteinase production of T lymphocytes (11). However, it is still unclear how the extract influences the production of inflammatory mediators. Therefore, the present study is aimed at demonstrating the role of AV-ext in the inhibition of TNF- $\alpha$ production in macrophages stimulated by LPS. We show that AV-ext can rescue animals from lethal sepsis through inhibiting the release of TNF- $\alpha$ from LPS-activated macrophages by down-regulating the activation of both MAPK and NF-KB signaling pathways. 
a

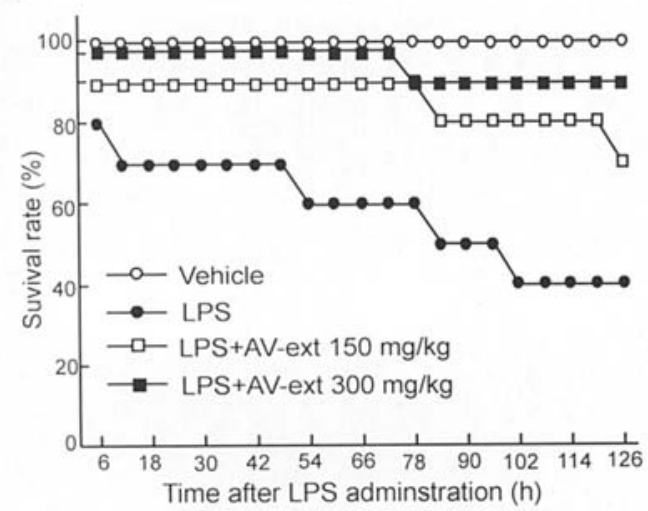

b

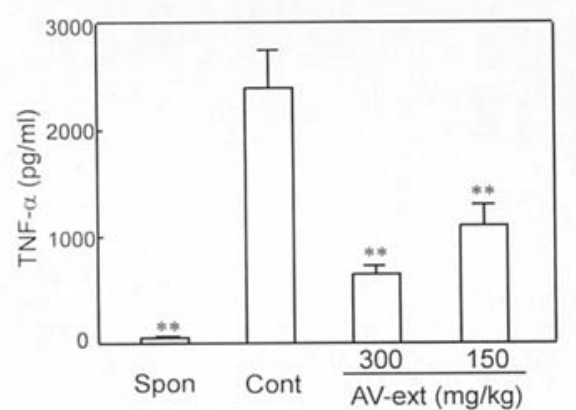

C

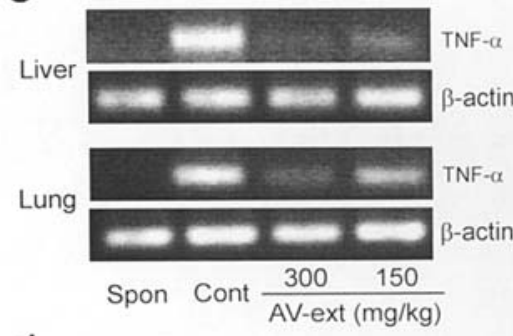

d

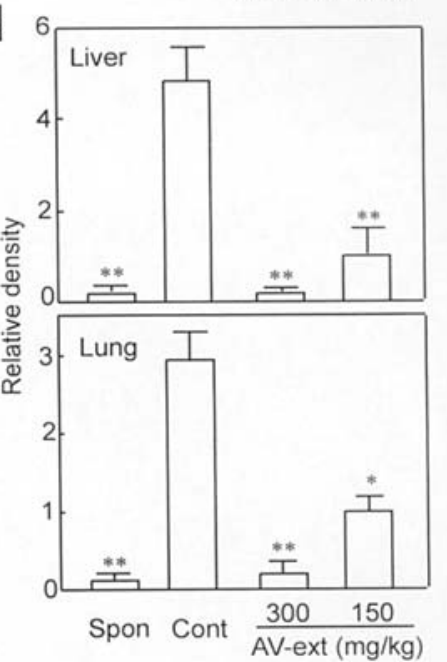

Figure 1. AV-ext attenuated LPS-induced mortality in mice. (a) AV-ext improved the survival of mice with LPS-induced sepsis. AV-ext (150 or 300 mg/kg) was orally administered for 1 day three times prior to LPS injection ( $5 \mathrm{mg} / \mathrm{kg}$ ). Each group includes 20 mice. (b) Serum TNF- $\alpha$ was measured using ELISA kits. AV-ext was orally administered for 1 day three times prior to LPS injection. Blood and tissue were collected $2 \mathrm{~h}$ after LPS treatment. Each column represents the mean \pm SD of 8 mice. (c) The TNF- $\alpha$ mRNA expression in the lung and liver tissues of LPS-treated mice was examined by RT-PCR. (d) The semiquantification results of TNF- $\alpha$ expression were determined using LabWorks 4.0 software. Each column indicates the mean \pm SD of the corresponding band intensities from three separate experiments. ${ }^{*} \mathrm{P}<0.05$ and ${ }^{* *} \mathrm{P}<0.01$ vs. control (Dunnett's test).

\section{Materials and methods}

Extracts and reagents. The aerial parts of Artemisia vestita were purchased from Tibet Pharmaceutical Factory of Tibet University (Lhasa, China) and identified as Artemisia vestita Wall. by Dr Ciren Dunzhu (Tibet College of Tibetan Medicine). The material herb was used to make the ethanol extract as previously reported (12). Briefly, the material (100 g) was extracted twice with 5-fold volumes of ethanol $(500 \mathrm{ml})$ at $70^{\circ} \mathrm{C}$ for $1 \mathrm{~h}$ each time. The supernatant was lyophilized to make a powder with a $10.1 \%$ yield. A stock solution of the extract was dissolved in DMSO and then diluted to at least 1,000-fold during cell culture. Other reagents used in this study were lipopolysaccharide (LPS; Sigma), ELISA kit for TNF- $\alpha$ (Duoset; Genzyme, Milan, Italy), RPMI-1640 (Gibco, NY), new bovine serum (NBS; Hangzhou Sijiqing Co., Ltd., Hangzhou, China), anti- $\alpha$ tubulin (TU-02, sc-8035), anti-IкB $\alpha$ and anti-phospho-IкB $\alpha$ (all from Santa Cruz Biotechnology Inc., CA). Anti-p38, anti-phospho-p38, anti-ERK1/2, antiphospho-ERK1/2, anti-JNK and anti-phospho-JNK were from Cell Signaling Technology, MA.

Animals. Specific pathogen-free male BALB/c mice, aged 6-8 weeks (22-25 g), were obtained from the Laboratory Animal Center of Shanghai (Shanghai, China). Animal welfare and experimental procedures were carried out in strict accordance with the Guide for the Care and Use of Laboratory
Animals (National Research Council of USA), and the related ethical regulations of our university.

Endotoxin shock in mice. Mice received $5 \mathrm{mg} / \mathrm{kg}$ of LPS intraperitoneally (i.p.), and the blood was collected $2 \mathrm{~h}$ after LPS administration. The samples were then centrifuged for $20 \mathrm{~min}$ at $1500 \mathrm{~g}$ and stored at $-70^{\circ} \mathrm{C}$ before analysis. Mouse mortality was recorded for up to 2 weeks after injection to ensure that no additional late deaths occurred (13).

Cell culture. Murine macrophage RAW 264.7 cells were cultured in RPMI-1640 medium supplemented with $100 \mathrm{U} \mathrm{ml}^{-1}$ of penicillin, $100 \mu \mathrm{g} \mathrm{ml}^{-1}$ of streptomycin and $10 \%$ new bovine serum in a humidified $5 \%(\mathrm{v} / \mathrm{v}) \mathrm{CO}_{2}$ atmosphere at $37^{\circ} \mathrm{C}$.

Preparation for peritoneal macrophage. Male BALB/c mice were intraperitoneally injected with $0.8 \mathrm{ml}$ of sodium carboxymethylcellulose (3\%). After 3 days, macrophages were collected from the peritoneal cavity and cultured in 96 -well plates $\left(5 \times 10^{5}\right.$ cells/well) at $37^{\circ} \mathrm{C}$ for $12 \mathrm{~h}$. The cells were then washed twice and stimulated with LPS.

Enzyme-linked immunosorbent assay of TNF- $\alpha$. TNF- $\alpha$ in the cell supernatant or serum was measured using a standard ELISA kit (Duoset). The concentrations of TNF- $\alpha$ in each sample were calculated from a standard curve using known concentrations of recombinant murine TNF- $\alpha$. 


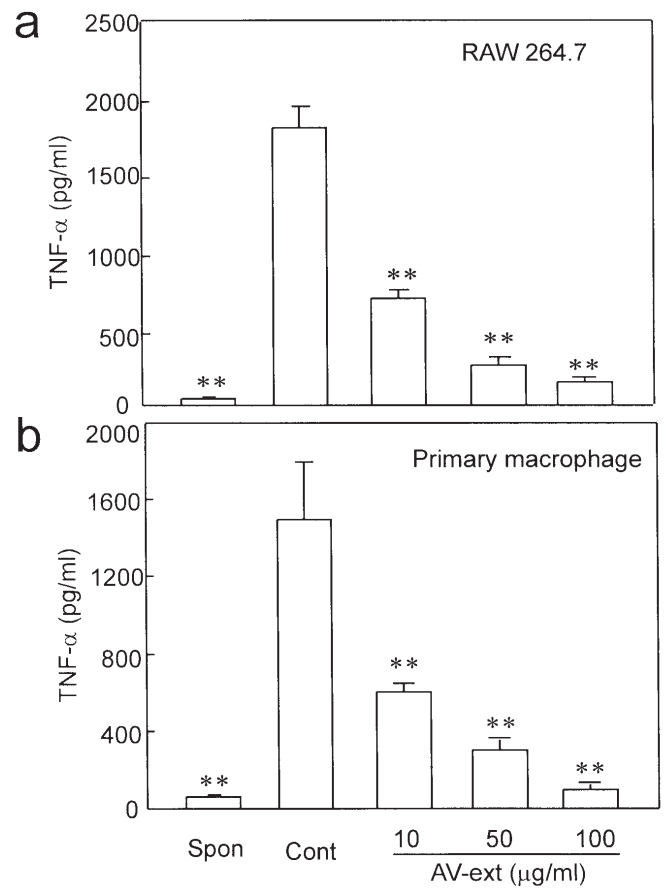

Figure 2. AV-ext inhibited the production of TNF- $\alpha$ in RAW 264.7 macrophages (a) and in primary peritoneal macrophages (b). The cells were pretreated with AV-ext for $1 \mathrm{~h}$, then stimulated with $1 \mu \mathrm{g} / \mathrm{ml}$ of LPS for $4 \mathrm{~h}$. Each column represents the mean \pm SD of three independent experiments in triplicate. ${ }^{*} \mathrm{P}<0.05$ and ${ }^{* *} \mathrm{P}<0.01$ vs. control (Dunnett's test).

Reverse transcriptase-polymerase chain reaction ( $R T-P C R)$. Total RNA was extracted from the cells or tissue of mice using Tripure reagent (Roche, IN). Single-stranded cDNA was synthesized from $2 \mu \mathrm{g}$ of total RNA by reverse transcription using $0.5 \mu \mathrm{g}$ primer of oligo(dT)18. Amplification was performed using the following primers (Genebase, Shanghai, China): ß-actin, forward 5'-ACATCTGCTGGAA GGTGGAC and reverse 5'-GGTACCACCATGTACCCAGG; TNF- $\alpha$, forward 5'-CATCTTCTCAAAATTCGAGTGACAA and reverse 5'-TGGGAGTAGACAAGGTACAACCC; IL-1ß, forward 5'-GCCCATCCTCTGTGACTC and reverse 5'-GCT CTGCTTGTGAGGTGC; COX-2, forward 5'-ACTCACTCA GTTTGTTGAGTCATTC and reverse 5'-GATTAGTACTGT AGGGTTAATG. PCR was performed at $94^{\circ} \mathrm{C}$ for $30 \mathrm{sec}$, $58^{\circ} \mathrm{C}$ for $1 \mathrm{~min}$ and $72^{\circ} \mathrm{C}$ for $1 \mathrm{~min}$. The number of cycles were $24,30,30$, and 26 for $\beta$-actin, TNF- $\alpha$, IL- $1 \beta$ and COX-2, respectively. After amplification, PCR products were separated by electrophoresis on $1.5 \%$ agarose gels and visualized using ethidium bromide. The relative expression was quantified densitometrically using LabWorks 4.0 software (UVP, CA) and calculated according to the reference bands of $\beta$-actin.

Western blot analysis. RAW 264.7 cells were extracted in lysis buffer consisting of $50 \mathrm{mM}$ Tris- $\mathrm{HCl}, \mathrm{pH} 8.0 ; 50 \mathrm{mM}$ $\mathrm{KCl}, 5 \mathrm{mM}$ DTT, 1 mM EDTA, $0.1 \%$ SDS, $0.5 \%$ Triton X-100 and protease inhibitor cocktail tablets (Roche). The extracted proteins were separated by SDS-PAGE and electrophoretically transferred onto polyvinylidene fluoride membranes. The membranes were probed overnight at $4^{\circ} \mathrm{C}$ with antibodies and then incubated with an HRP-coupled secondary antibody. Detection was performed using a LumiGlo chemiluminescent substract system (KPL, Guildford, UK).
Determination of active $N F-\kappa B$ by electrophoretic mobility shift assay. Nuclear extracts of the cells were prepared using a NucBuster ${ }^{\mathrm{TM}}$ protein extraction kit (Novagen, Darmstadt, Germany) according to the manufacturer's instructions. The double-stranded oligonucleotide probe containing a consensus binding sequence for NF-кB (5'-TAGTTGAGGGGACTT TCCCAGGCA-3'; Invitrogen, Shanghai, China) was 3' endlabeled with a digoxigenin-11-ddUTP using a DIG Gel Shift kit (Roche). Five $\mu \mathrm{g}$ of nuclear protein was incubated in a $20 \mu \mathrm{l}$ reaction volume on ice for $1 \mathrm{~h}$ and then loaded onto a $6 \%$ nondenaturing polyacrylamide gel in $0.5 \mathrm{X}$ Tris-borateethylenediaminetetraacetic acid buffer at $4^{\circ} \mathrm{C}$. The bands were detected by anti-digoxigenin-alkaline phosphatase and the luminogenic substrate, CSPD. The specificity of the DNA-protein complex was confirmed by competition with a 100 -fold excess of unlabeled NF- $\mathrm{BB}$ and AP-2 (5'-GATCG AACTGACCGCCCGCGGCCCGT-3'; Invitrogen) binding sequences, respectively.

Transient transfection and luciferase assay. NF-кB-luc and $ß$-galactosidase plasmid were kind gifts from Dr Zi-Chun Hua, Nanjing University, Nanjing. RAW 264.7 cells were transfected with $\mathrm{NF}-\kappa \mathrm{B}-1 \mathrm{c}$ c reporter plasmids using Lipofectamine $^{\mathrm{TM}} 2000$ transfection reagent (Invitrogen). $\beta$-galactosidase control plasmid was cotransfected as an internal control for transfection efficiency. After $48 \mathrm{~h}$, cells were harvested. In the LPS treatment experiment, $42 \mathrm{~h}$ after transfection, the cells were incubated with indicated reagents for $1 \mathrm{~h}$ and then treated with LPS $(1 \mu \mathrm{g} / \mathrm{ml})$ for $5 \mathrm{~h}$. Luciferase activity was assayed using a luciferase assay kit (Promega, WI). Luminescence was measured using a luminometer (Turner Design, Sunnyvale, CA). ß-galactosidase activity was measured using a $\beta$-galactosidase assay kit (Invitrogen). The transfection efficiencies were normalized by $ß$-galactosidase activity.

Statistical analysis. Results were expressed as mean \pm SD. Statistical evaluation was performed by Student's t-test when only two value sets were compared, and one-way ANOVA followed by Dunnett's test when the data involved three or more groups. $\mathrm{P}<0.05$ was considered to be significant.

\section{Results}

Pretreatment with AV-ext prevents LPS-induced mortality in mice through decreasing TNF-a levels. Both doses of AV-ext (150 and $300 \mathrm{mg} / \mathrm{kg}$ ) conferred significant protection from lethal endotoxemia (Fig. 1a), including the clinical manifestations of endotoxin morbidity, such as decreased activity, lethargy, diarrhea and huddling. Late deaths in AV-exttreated animals were not observed within 2 weeks after LPS injection. As shown in Fig. 1b, the elevation of serum TNF- $\alpha$ after LPS treatment was dose dependently inhibited by AV-ext. Furthermore, AV-ext dramatically suppressed the expression of TNF- $\alpha$ mRNA both in the liver and lung tissues from experimental sepsis mice in a dose-dependent manner compared with the control group (Fig. 1c and d).

AV-ext inhibits the production of TNF- $\alpha$, both in RAW 264.7 macrophages and primary peritoneal macrophages activated 
a

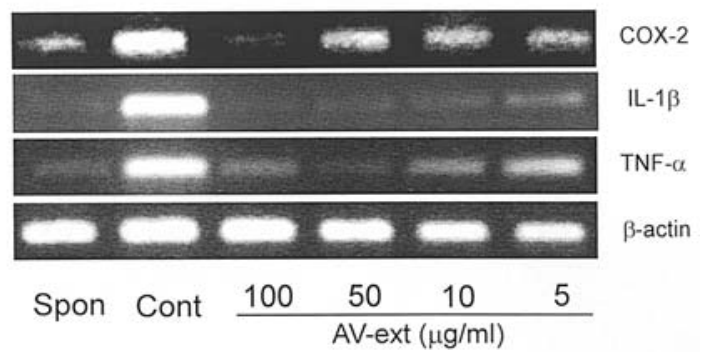

b

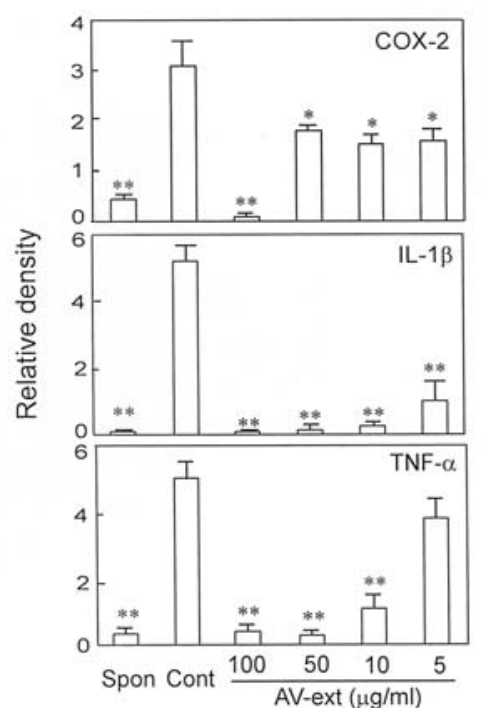

Figure 3. AV-ext dose dependently suppressed TNF- $\alpha$, IL-1ß and COX-2 expression in RAW 264.7 cells. (a) RAW 264.7 cells were pre-incubated with the indicated doses of AV-ext for $1 \mathrm{~h}$ and then stimulated with $1 \mu \mathrm{g} / \mathrm{ml}$ of LPS for $2 \mathrm{~h}$. The cells were lysed, and total RNA was prepared for RTPCR analysis. (b) Semiquantitative data of the above results. Each column indicates the mean \pm SD of the corresponding band intensities from three separate experiments. ${ }^{*} \mathrm{P}<0.05$ and ${ }^{* *} \mathrm{P}<0.01$ vs. control (Dunnett's test).

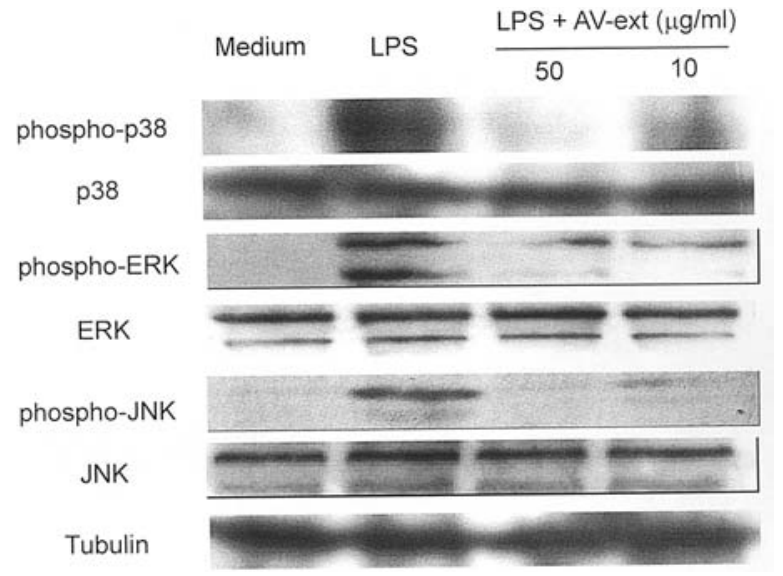

Figure 4. AV-ext reduced the LPS-induced phosphorylation of p38, ERK1/2 and JNK. RAW 264.7 cells were pretreated with or without AV-ext for $1 \mathrm{~h}$ and then stimulated with $1 \mu \mathrm{g} / \mathrm{ml}$ of LPS for $30 \mathrm{~min}$. Then cell lysates were analyzed by immunoblotting. One representative experiment of three is shown.

by LPS. RAW 264.7 cells and primary peritoneal macrophages were pretreated with various concentrations of AV-ext and then exposed to LPS. As shown in Fig. 2, pretreatment with AV-ext notably inhibited LPS-induced TNF- $\alpha$ production in a concentration-dependent manner. It is notable that the viability of these cells was $>95 \%$ in both high dose AV-exttreated and untreated cells, as measured by trypan blue exclusion and annexin V-propidium iodide staining (data not shown).

$A V$-ext inhibits TNF- $\alpha, I L-1 \beta$ and COX-2 expression in RAW 264.7 macrophages induced by LPS. LPS stimulation
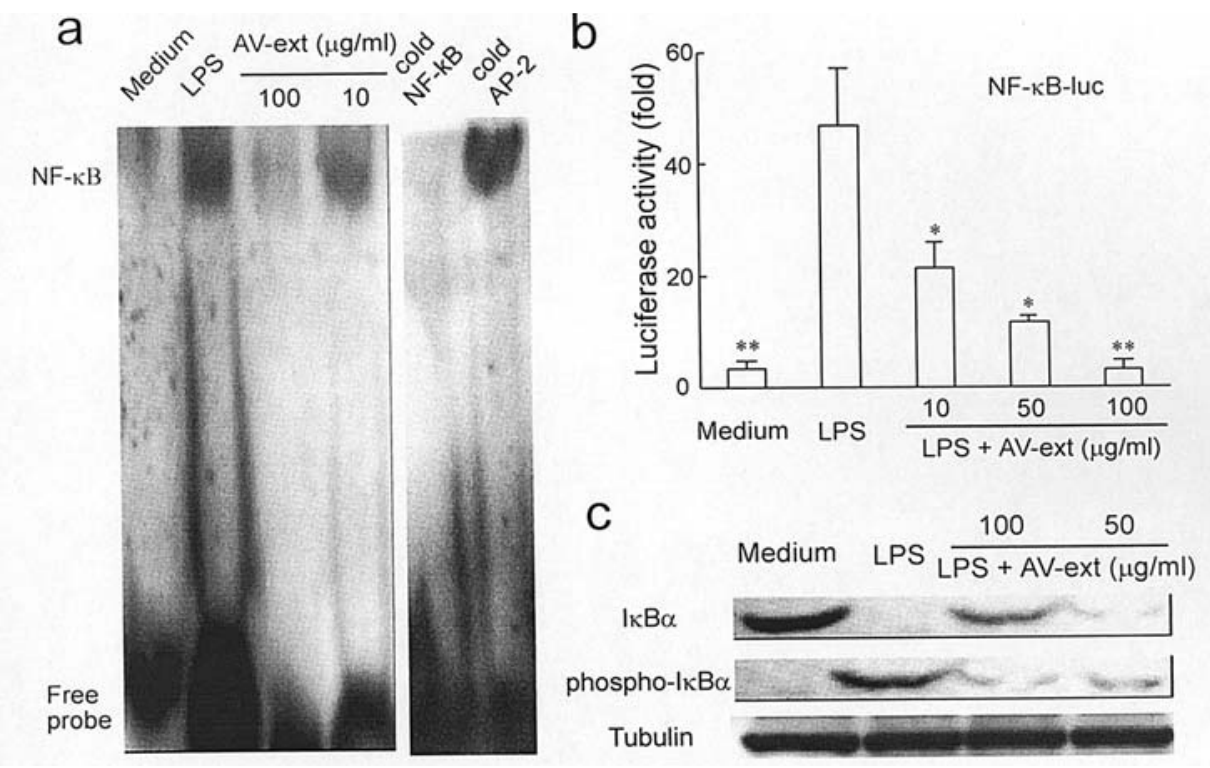

Figure 5. AV-ext inhibited LPS-mediated NF- $\kappa$ B activation, I $\mathrm{B} \alpha$ phosphorylation and degradation. (a) To measure NF- $\kappa \mathrm{B}$ DNA binding activity, RAW 264.7 macrophages were pre-incubated for $1 \mathrm{~h}$ with the indicated doses of AV-ext and then stimulated with $1 \mu \mathrm{g} / \mathrm{ml}$ of LPS for $1 \mathrm{~h}$. The nuclear extracts were assayed by EMSA. One representative experiment of three is shown. (b) To measure NF-kB transcription activity, RAW 264.7 cells were transfected with the NF-kB-luc reporter gene for $42 \mathrm{~h}$. The cells were pre-incubated for $1 \mathrm{~h}$ with the indicated doses of AV-ext before stimulation with $1 \mu \mathrm{g} / \mathrm{ml}$ of LPS for $5 \mathrm{~h}$. Each column represents the mean \pm SD of three independent experiments. ${ }^{*} \mathrm{P}<0.05$ and ${ }^{* *} \mathrm{P}<0.01$ vs. LPS-activated cells (Dunnett's test). (c) To measure I $\mathrm{B} \alpha$ degradation and phosphorylation, RAW 264.7 macrophages were pretreated with indicated doses of AV-ext for $1 \mathrm{~h}$ before stimulation with $1 \mu \mathrm{g} / \mathrm{ml}$ of LPS for $30 \mathrm{~min}$. Cell lysates were probed by Western blot analysis. One representative experiment of three is shown. 
triggered the expression of proinflammatory cytokines in the macrophages. Against this, AV-ext showed significant inhibition of the expression of cytokines such as TNF- $\alpha$, IL-1ß and COX-2 (Fig. 3).

$A V$-ext reduces the LPS-induced activation of p38, ERK1/2 and JNK in RAW 264.7 macrophages. As revealed by Western blot analysis with antibodies specific for the phosphorylated form of p38, ERK1/2 and JNK, pretreatment with AV-ext dose dependently inhibited the LPS-induced phosphorylation of these MAPKs (Fig. 4). However, AV-ext did not influence the total cellular expression of $\mathrm{p} 38$, ERK1/2 and JNK.

$A V$-ext inhibits $N F-\kappa B$ activation and prevents IкBa phosphorylation and degradation. As shown in Fig. $5 \mathrm{a}, \mathrm{NF}-\kappa \mathrm{B}$ binding activity was significantly inhibited by AV-ext in a dose-dependent manner. We used the constructed luciferase receptor plasmid NF- $\mathrm{NB}$-luc to investigate the effect of $\mathrm{AV}$-ext on $\mathrm{NF}-\kappa \mathrm{B}$ transcription activity. As a result, AV-ext dose dependently decreased NF- $\mathrm{B}$ transcription activity in RAW 264.7 cells (Fig. 5b). Furthermore, AV-ext remarkably inhibited LPS-mediated I $\mathrm{B} \alpha$ phosphorylation and degradation in a concentration-dependent manner (Fig. 5c).

\section{Discussion}

Macrophages play an important role in the regulation of inflammation and immune response. Upon activation, macrophages release various growth factors, cytokines and lipid mediators, which promote inflammation by directing cellular migration to the site of inflammation. Among them, TNF- $\alpha$ is one of the most important cytokines. It has been shown that inhibiting the action of TNF- $\alpha$ could prevent the development and progression of autoimmunity diseases in experimental models (13-15). These findings have raised great interest in identifying inhibitors of $\mathrm{TNF}-\alpha$ production to treat $\mathrm{TNF}-\alpha$-related diseases such as rheumatoid arthritis, inflammatory bowel disease and sepsis. In this study, we demonstrated that the extract from Artemisia vestita, a traditional Tibetan medicine, inhibited TNF- $\alpha$ production both in vivo and in vitro. We found that pretreatment with AV-ext dramatically ameliorated LPS-induced mortality in mice and significantly inhibited the secretion of TNF- $\alpha$ into the serum (Fig. 1a and b). In addition, the exposure to LPS can also induce hepatitis and acute lung injury in mice, which leads to a large increase in TNF- $\alpha$ production by macrophage/ Kuppfer cells (16). In contrast, pretreatment with AV-ext dose dependently suppressed TNF- $\alpha$ expression, both in the liver and lung tissues (Fig. 1c and d). Our data hereby demonstrate the potential anti-inflammatory action of AV-ext in vivo. To further confirm the anti-inflammatory effect of AV-ext, we also examined whether AV-ext could exert its inhibitory effect on the macrophage cell line, RAW 264.7, in vitro. As a result, treatment with $10^{-4} \mathrm{~g} / \mathrm{ml}$ of $\mathrm{AV}$-ext significantly decreased TNF- $\alpha$ production, both in RAW 264.7 cells (Fig. 2a) and primary peritoneal macrophages (Fig. 2b) stimulated by LPS. In addition to the inhibitory effect on the protein level, AV-ext also markedly reduced the transcriptional activities of proinflammatory cytokines such as TNF- $\alpha$, IL-1ß, and COX-2 (Fig. 3). These results suggest that $\mathrm{AV}$-ext has a potent inhibitory effect on proinflammatory cytokines, especially TNF- $\alpha$.

Several kinases, such as protein kinase C, cAMP-dependent protein kinase $\mathrm{A}$ and protein tyrosine kinases, have been found to be important in TNF- $\alpha$ regulation in different cell types and species. These kinases may in turn activate kinases that are downstream in the signaling cascade, such as mitogenactivated protein kinases (MAPKs), which play a central role in cytokine production and mediation of cellular stress response $(17,18)$. The inhibitory effect of AV-ext on the TNF- $\alpha$ level suggested that AV-ext might modulate intracellular signaling events which coordinate the activity of proinflammatory cytokines. Signal transduction through ERK1/2, JNK and p38 MAPK pathways is a critical step in macrophage activation leading to increased expression of proinflammatory cytokines. To better understand the molecular mechanisms underlying the anti-inflammatory effect of AV-ext, we further examined the effect of AV-ext on LPS-induced activation of MAPK signaling pathways. As a result, AV-ext dose dependently inhibited LPS-evoked phosphorylation of p38, ERK1/2 and JNK in RAW 264.7 cells (Fig. 4), while the extract did not influence the total protein expression. These results suggest that the inhibitory effect of AV-ext on the expression of inflammatory cytokines involves the suppression of MAPK signaling pathways.

One important signaling pathway in the induction of TNF- $\alpha$ expression is the activation of nuclear transcription factor NF- $\mathrm{KB}$ (6). Consistent with the inhibition on TNF- $\alpha$ expression (Figs. 1c and 3) and production (Figs. 1b and 2), AV-ext markedly blocked NF- $\mathrm{BB}$ activation, both in DNA binding activity (Fig. 5a) and transcription activity (Fig. 5b), in the macrophage induced by LPS. The activity of NF- $\kappa \mathrm{B}$ is regulated by an inhibitory protein, IкB, which forms a complex with $\mathrm{NF}-\kappa \mathrm{B}$, keeping $\mathrm{NF}-\kappa \mathrm{B}$ in an inactive state in the cytoplasm. When cells are activated, the inhibitory proteins undergo phosphorylation, which subsequently leads to the degradation of IкB. The loss of IкB results in the release of free NF-кB units that translocate from the cytoplasm to the nucleus, where they may trigger the transcription of specific target genes. Futhermore, we found that pretreatment with AV-ext significantly inhibited LPS-mediated IкB $\alpha$ phosphorylation and degradation in a dose-dependent manner (Fig. 5c). The result revealed that AV-ext affected the activation of NF- $\kappa \mathrm{B}$, probably through inhibiting I $\mathrm{B} \alpha$ degradation and phosphorylation. We speculate that $\mathrm{AV}$-ext blocks $\mathrm{NF}-\kappa \mathrm{B}$ activation, subsequently inhibits the transcription of TNF- $\alpha$, which is the target gene of NF- $\mathrm{KB}$, and finally protects mice from LPS-induced sepsis. In fact, aqueous extract from the same genus plant, Artemisia capillaris, also alleviated liver inflammatory diseases by preventing NF-кB activation (19), suggesting that similar active components in these extracts are from the same genus plant. Analysis of the active chemical components in AV-ext is now in progress.

In conclusion, we demonstrated that AV-ext inhibits LPS-induced TNF- $\alpha$ and other proinflammatory cytokine production, both in vivo and in vitro, and exerts its antiinflammatory effects through inhibiting LPS-induced activation of the MAPK and NF-кB pathways in macrophages. Thus, $\mathrm{AV}$-ext may be beneficial in clinical applications for inflammatory diseases. 


\section{Acknowledgements}

This study was supported by the National Natural Science Foundation of China (no. 30230390), Major State Basic Research Development Program (973 program) of China (no. 2002CB513004) and Post-doctorate Program Foundation of China (no. 2005037722).

\section{References}

1. Frost RA, Nystrom GJ and Lang CH: Lipopolysaccharide regulates proinflammatory cytokine expression in mouse myoblasts and skeletal muscle. Am J Physiol Regul Integr Comp Physiol 283: 698-709, 2002.

2. Jones BW, Means TK, Heldwein KA, Keen MA, Hill PJ, Belisle JT and Fenton MJ: Different Toll-like receptor agonists induce distinct macrophage responses. J Leukoc Biol 69: 1036-1044, 2001.

3. Hsu HY and Wen MH: Lipopolysaccharide-mediated reactive oxygen species and signal transduction in the regulation of interleukin-1 gene expression. J Biol Chem 277: 22131-22139, 2002.

4. Czura CJ, Yang H, Amella CA and Tracey KJ: HMGB1 in the immunology of sepsis (not septic shock) and arthritis. Adv Immunol 84: 181-200, 2004.

5. Means TK, Pavlovich RP, Roca D, Vermeulen MW and Fenton MJ: Activation of TNF- $\alpha$ transcription utilizes distinct MAP kinase pathways in different macrophage populations. J Leukoc Biol 67: 885-893, 2000.

6. Celec P: Nuclear factor kappa B-molecular biomedicine: the next generation. Biomed Pharmacother 58: 365-371, 2004.

7. Viatour P, Merville MP, Bours V and Chariot A: Phosphorylation of NF-кB and IкB proteins: implications in cancer and inflammation. TRENDS Biochem Sci 30: 43-52, 2005.

8. Lee JH, Choi YH, Kang HS and Choi BT: An aqueous extract of Platycodi radix inhibits LPS-induced NF- $\mathrm{\kappa B}$ nuclear translocation in human cultured airway epithelial cells. Int J Mol Med 13: 843-847, 2004.
9. Kiemer AK, Hartung T, Huber C and Vollmar AM: Phyllanthus amarus has anti-inflammatory potential by inhibition of iNOS, $\mathrm{COX}-2$, and cytokines via the NF-кB pathway. J Hepatol 38: 289-297, 2003.

10. Qiangba CL, Gama QP, Zhan D and Riren BZ: Zhong Hua Ben Cao, Volume of Tibetan Medicine. Shanghai Science and Technology Press, Shanghai, pp260-261, 2002.

11. Wang JL, Sun Y, Li YH and Xu Q: Aqueous extract from aerial parts of Artemisia vestita, a traditional Tibetan medicine, reduces contact sensitivity in mice by down-regulating the activation, adhesion and metalloproteinase production of $\mathrm{T}$ lymphocytes. Int Immunopharmacol 5: 407-415, 2005.

12. Sun Y, Chen T and Xu Q: Si-Ni-San, a traditional Chinese prescription, and its drug pairs suppress contact sensitivity in mice via inhibiting activities of metalloproteinases and adhesion of T lymphocytes. J Pharm Pharmacol 55: 839-846, 2003.

13. Wang $\mathrm{H}$, Liao H, Ochani M, Justiniani M, Lin X, Yang L, Al-abed Y, Wang H, Metz C, Miller EJ, Tracey KJ and Ulloa L: Cholinergic agonists inhibit HMGB1 release and improve survival in experimental sepsis. Nat Med 10: 1216-1221, 2004.

14. Reimold AM: TNF-alpha as therapeutic target: new drugs, more applications. Curr Drug Targets Inflamm Allergy 1: 377-392, 2002.

15. Dinarello CA: Anti-cytokine therapeutics and infections. Vaccine 21(suppl 2): 24-34, 2003.

16. Blackwell TS, Yull FE, Chen CL, Venkatakrishnan A, Blackwell TR, Hicks DJ, Lancaster LH, Christman JW and Kerr LD: Multiorgan nuclear factor kappa B activation in a transgenic mouse model of systemic inflammation. Am J Respir Crit Care Med 162: 1095-1101, 2000.

17. Rao KM: MAP kinase activation in macrophages. J Leukoc Biol 69: 3-10, 2001.

18. Jiang JX, Zhang Y, Ji SH, Zhu P and Wang ZG: Kinetics of mitogen-activated protein kinase family in lipopolysaccharidestimulated mouse Kupffer cells and their role in cytokine production. Shock 18: 336-341, 2002.

19. Hong SH, Seo SH, Lee JH and Choi BT: The aqueous extract from Artemisia capillaris Thunb. inhibits lipopolysaccharideinduced inflammatory response through preventing NF-кB activation in human hepatoma cell line and rat liver. Int $\mathrm{J}$ Mol Med 13: 717-720, 2004. 